\title{
多目的最適化解析によるテンション構造の最大剛性形態 \\ MULTICRITERIA OPTIMIZATION FOR MAXIMUM RIGIDITY AND MINIMUM VOLUME OF TENSION STRUCTURES
}

\author{
陳 沛山*, 川口 衞** \\ Pei Shan CHEN and Mamoru KAWAGUCHI
}

\begin{abstract}
Structural shape optimization always adopts structural analysis. For such a reason, the solution of a shape optimization always depends on the loading pattern (loading cases), and it is not so easy to obtain a unique optimum solution for a structure subjected to different loading cases. By weighting function method, the present paper promotes a multicriteria optimization method to maximize the rigidity and minimize the volume (the total volume of all members) of a tension structure subjected to different loading cases. With a purpose of minimizing the nodal displacement vector and the volume, a nonlinear programming method is adopted in the analysis to find the optimum nodal coordinates, member section areas and the distribution of prestresses.

A tensegrity frame is taken as a numerical example, and the results show $24.5 \%$ reduction in the volume and that some of the nodal displacements can be reduced $10 \%$, or $30 \%$ of their initial values.
\end{abstract}

\section{1. はじめに}

多目的最適化解析(multiobjective / multicriteria optimization)は、本世紀初期ごろに、フランスの経済学者 V. Pareto により発案された"1) 長い年月を経て、1970年代 に、W. Stadlerらは初めて技術領域におけるべクトル最 適化(vector optimization) の応用を研究した2)。以来、構 造分野においては最小コスト形態に関する研究が主流 になっている。近年、コンピュータの大容量化亡高速 化に伴い、形態最適化 (shape optimization)についての 研究も多様化になって、数多くの文献が発表されてい る。筆者はテンション構造の剛性問題に着目し、ベク トル最適化手法を採り入れ、最大剛性形態（最小変位 形態）理論を提案した

テンション構造は幾何学的不安定構造が多く、全体 剛性が低いことが消極的特徵の一つになっている。通 常、㓮性を高めるためには高いプレストレスの導入が 試みられるが、これは一般的に不経済であり、また工
事上の困難を伴う場合もある。従って、テンション丵 造の最大㴊性形態を求める研究が重要な意味を持つよ うになる。また、このような研究を通じてテンション 構造の形態設計に理論的な根拠を与える可能性も期待 できる。

構造の形態最適化解析には、構造解析を含む場合が 多いため、その最適解（最適形態）が荷重パターンに 依存することが明らかである。そして、多種類荷重パ ターンに対する統一的な最適解を求める研究が必要で ある。

前段階の研究において、筆者は 2 種類の最大剛性形 態理論を提案した。これは、幾何学的非線形構造解析 之非線形計画法を組み合わせる方法, ${ }^{3}$, 2 線形構造解析

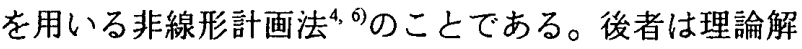
析む簡明で、コンピュータ・プログラムの編成も容易 であり、計算速度をアップさせることができ、多目的 㵊適化解析に適用する万法である。しかし、これらの
* 法政大学大学院工学研究科 大学院生.工修

** 法政大学工学部建築学科 教授. 工博
Doctoral Student, Graduate School Hosei University, M. Eng. Prof., Dept. of Architecture, Hosei University, Dr. Eng. 
最適化手法は一種類の荷重パターンに対する理論であ る。本論文は、前述の後者の解析手法より延長し、重 み関数法（線形加重法、weighting function）を用いて、 多種の荷重パターンに対してテンション棈造の剛性を 高めると共に部材の占める体積（以下ボリュームと呼 ぶ）を最小化することを試みる。

但し、線形構造解析によるテンション構造の解析は 近似的であるため、線形構造解析を用いる最適化解析 により得られる最適形態屯近似的な結果であると考え られる。ゆえに、本解析により得られる最適形態に対 して、幾何学的非線形構造解析を行って、構造の剛性 変化の有無を検証することが必要である。

本論文には、 tensegrity 構造を例題として数値解析を 行い、数值的な例示を行った。その結果、ボリューム は24.6\%減り、節点変位は $10 \%$ 30\% 減少し、特に非対 称荷重に対する全体剛性が高くなることが確認された。

\section{2. 問題及び基本概念}

2.1 問題とその数学モデル

本研㭝では、ある一定な荷重レベルにおいて節点変 位（変位べクトルの大きさ）を最小化することにより、 荷重変位曲線の勾配を大きくさせ、棈造の全体㓮性を 高める最適化解析を展開する ${ }^{3-0}$ 。最適化解析の目的関 数は式(1)〜(4)で表される。

$$
\begin{aligned}
& f_{i}=\sum_{i=1}^{n} D_{i}^{2} \mid \text { for loading cisse } 1
\end{aligned}
$$

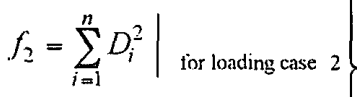

$$
\begin{aligned}
& \begin{array}{llllll}
\ldots & \ldots & \ldots & \ldots & \ldots
\end{array} \\
& f_{i}=\sum_{i=1}^{n} D_{i}^{2} \mid \text { tor loading case } \iota \\
& F_{1}=w_{1} f_{1}+w_{2} f_{2}+\ldots+w_{l} f_{l} \\
& F_{2}=\sum_{k=1}^{m} L_{k} A_{k}=\mathbb{L}^{\top} \mathbb{A}
\end{aligned}
$$

$こ こ に 、 \mathbb{D}=\left\{D_{i}\right\}$ は節点変位ベクトル、 $\mathbb{A}=\left\{A_{k}\right\}$ は部 材の断面積ベクトル、 $\mathbb{L}=\left\{L_{k}\right\}$ は部材の長さであり、 mは部材の数、 $n$ は棈造の自由度数である。 $F_{1}$ を剛性

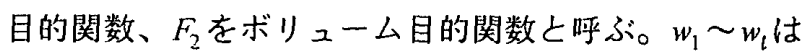
重み係数 (weighting factor) ${ }^{7,8)}$ である。但し、 $\sum_{j} w_{j}=1$ 。

本解析の最適化問題は次のように表される。

$$
\left\{\begin{aligned}
\text { minimize } & F=\mathscr{W}_{1} F_{1}+\mathscr{W}_{2} F_{2} \\
\text { subject to : } & \\
\phi_{j}(\mathrm{X}, \mathbb{A}, \mathbb{P}) & =0 ; \quad(j=1, \ldots, s) \\
\varphi_{k}(\mathrm{X}, \mathbb{A}, \mathbb{P}) & \leq 0, \quad(k=1, \ldots, t)
\end{aligned}\right.
$$

ここに、 $\mathbf{X}=\left\{x_{i}\right\}$ は節点座標ベクトル、 $\mathbf{P}=\left\{P_{k}\right\}$ は部 材のプレストレス軸力ベクトルである。式(5)は等式拘 束条件 (equality constrains)、式(6)は不等式拘束条件 (inequality constrains)を示している。本解析では、㓮性 目的関数 $F_{1}$ には距離関数法(distance function) ${ }^{7,8)}$ と重み 関数法を、目的関数 $F に は$ 重み関数法を採り入れてい る。 $W_{1}, W_{2}$ はその重み係数である。但し、 $W_{1}+W_{2}=1$ 。

この最適化問題は、拘束条件(5)之(6)を満足しながら 未定変数 $(\mathbf{X}, \mathbb{A}, \mathbb{P})$ (以下設計変数と呼ふ）を挆查する ことにより目的関数 $F を$ 最小にすることである。

但し、テンション構造の解析は一般に三段階に分け て行う。これは、プレストレス導入前の形態解析、プ レストレス導入によもなう変形解析、そしてプレスト レスを導入した後の付加荷重に対する変形解析である。 ここに、XはプレストレスPを導入した後の構造形態 の節点座標であり、変位Dはプレストレス $\mathbb{P}$ 導入し た後の荷重により生じるものである。そして、プレス トレス導入前の形態（節点座標）は本解析の最終結果 $\mathrm{X}, \mathbb{A}, \mathbb{P}$ により得られる。

\section{2 支配方程式}

剛性目的関数 $F_{1}$ とX,A, $\mathbb{P}$ との間の関数関係式を支配 方程式と呼ふ。この支配方程式はテンション構造の線 形解析の基本式の何れか、あるいは何らかの手法で構 造を近似的に線形解析できるような解析式である。荷 重が十分小さい場合、支配方程式は次式のように表さ れる。

$$
\mathbb{K D}=\mathbb{Q} .
$$

ここに、 $\mathbb{K}$ は構造の剛性マトリックスであり、QQQ荷 重ベクトルである。KにはプレストレスPにより与ら れた幾何㓮性マトリックスが含まれているき。

\section{3 拘束条件についてで们}

拘束条件には、常に等式条件と不等式条件、さらに 幾何学的拘束条件亡力学的拘束条件が含まれている。

幾何学的拘束条件は建築計画あるいは構造計画の要 求や建物の目的などにより与えられる。力学的拘束条 件は構造の特徵に合わせて力学原理により与えられる。

建築計画の要求や構造的な条件などの存在は当然の ことであり、設計変数に拘束条件が付くことも必要で ある。これらの拘束条件が設計変数の拘束空間(許容空 間、設計空間）を与える。 


\section{3. 最適化解析}

\section{1 目的関数の降下方向}

本解析は、非線形計画法を用いて、拘束空間におい て目的関数の減少方向（降下方向）に沿って設計変数 を修正することにより最適解を得る。

剛性目的関数の降下方向は目的関数の設計変数によ る微分のベクトルである。式 (7)を微分すると

$$
\begin{aligned}
& \dot{\mathbf{K}} \mathbf{D}+\mathbf{K} \dot{\mathbf{D}}=\dot{\mathbf{Q}} \\
& \dot{\mathbf{D}}=\mathbf{K}^{-1}(\dot{\mathbf{Q}}-\dot{\mathbf{K}} \mathbf{D})
\end{aligned}
$$

を得る。ここに、ロは設計変数 $\mathbf{X}, \mathbf{A}, \mathbf{P}$ による微分を 示す。徒って、剛性目的関数の降下方向は次式のよう になる。

$$
\tilde{\mathbf{d}}^{\mathrm{T}}=-2 \mathbf{D}^{\mathrm{T}}(\mathbf{D} \nabla)
$$

但し、 $\nabla=\left(\frac{\partial}{\partial x_{1}}, \ldots, \frac{\partial}{\partial x_{n}}, \frac{\partial}{\partial A_{1}}, \ldots, \frac{\partial}{\partial A_{m}}, \frac{\partial}{\partial P_{1}}, \ldots, \frac{\partial}{\partial P_{m}}\right)$ 。式 (8)〜(10) は一つの荷重パターンに対する解析である。 多種な荷重パターンの場合、 $F_{1}$ の降下方向は次のよう になる。

$$
\nabla^{\mathrm{T}} F_{1}=\sum_{i=1}^{i} w_{i} \tilde{\mathbf{d}}_{i}
$$

ここに、 $i=1,2, \ldots \ell$ は荷重パターンを表している（式 (1)之式(2)を参照)。

ボリューム目的関数(3)の隆下万问は次式のように表 される。

$$
\nabla^{\mathrm{T}} F_{2}=(\mathbf{L} \nabla)^{\mathrm{T}} \mathbf{A}+\mathbf{L}^{\mathrm{r}}(\mathbf{A} \nabla)
$$

従って、目的関数 $F$ の降下方向は次式のようになる。

$$
\hat{\mathbf{d}}=\mathscr{W}_{1} \nabla^{\mathrm{T}} F_{1}+\mathscr{W}_{2} \nabla^{\mathrm{T}} F_{2}
$$

\section{2 座標変換}

棈造形態は半径やライズ等の基本寸法だけで定めら れる場合が多い。また、一部分の部材のプレストレス を先に与えれば、釣り合い条件により構造全体のプレ ストレスを定めることができる。ここで、これらの基 本寸法や先に与える一部分のプレストレスを設計パラ メー夕と呼ぶ。従って、設計変数 $\mathbf{X}, \mathbf{A}, \mathbf{P}$ はそれぞれ の設計パラメータの関数として裴される。

$$
\mathbf{X}=\boldsymbol{g}\left(q_{1}, q_{2} \ldots, q_{r}\right)
$$

$$
\mathbf{A}=\boldsymbol{h}\left(a_{1}, a_{2}, \ldots, a_{\beta}\right)
$$

$$
\mathbf{P}=u\left(\rho_{1}, \rho_{2}, \ldots, \rho_{\gamma}\right) \quad .
$$

ここに、 $\mathbf{q}=\left\{q_{i}\right\} ; \mathbf{a}=\left\{a_{j}\right\} ; \mathbf{p}=\left\{\boldsymbol{\rho}_{k}\right\}$ はそれぞれ節点 座標、部材断面積とプレストレスの設計パラメータを 示している。

もし、\{ $\left\{q_{i}\right\},\left\{a_{j}\right\},\left\{\rho_{k}\right\}$ は独立変数であり、有効拘束 条件が付いていなければ、式(14)〜(16)の変換のJacobi マトリックスは

$$
\begin{aligned}
& \boldsymbol{J}_{\boldsymbol{x}}=\left[\frac{\partial g_{i}}{\partial q_{j}}\right] ; \\
& (i=1,2, \ldots, n ; j=1,2, \ldots, r) \\
& \boldsymbol{J}_{A}=\left[\frac{\partial h_{i}}{\partial a_{j}}\right] ; \\
& (i=1,2, \ldots, m ; j=1,2, \ldots, \beta) \\
& \boldsymbol{J}_{P}=\left[\frac{\partial u_{i}}{\partial p_{j}}\right] ; \\
& (i=1,2, \ldots, m ; j=1,2, \ldots, \gamma) \\
& \boldsymbol{J}=\left[\begin{array}{lll}
\boldsymbol{J}_{\boldsymbol{x}} & \\
& \boldsymbol{J}_{A} & \\
& & \boldsymbol{J}_{P}
\end{array}\right]
\end{aligned}
$$

となる。そして、設計パラメータにおける目的関数 の降下方向

$$
\mathbf{d}=J \hat{\mathbf{d}}
$$

が得られる。但し、

$$
\begin{aligned}
\mathbf{d}=( & \left(\frac{\partial F}{\partial q_{1}}, \ldots, \frac{\partial F}{\partial q_{r}},\right. \\
& \left.\frac{\partial F}{\partial a_{1}}, \ldots, \frac{\partial F}{\partial a_{\beta}}, \frac{\partial F}{\partial \rho_{1}}, \ldots, \frac{\partial F}{\partial \rho_{\gamma}}\right)^{\mathrm{T}}
\end{aligned}
$$

また、設計変数 X,A,Pを他の一般座標系へ変換せず に解析を行うこともできる(文献4，6)を参照）。設計変 数 $\mathbf{X}, \mathbf{A}, \mathbf{P}$ は $\mathbf{n}=n+2 m$ 個の成分があり、与えられた等式 拘束条件(5)は $s$ 個ある。従って、設計変数のうちに、 $r=\mathrm{n}-s$ 個の独立成分で $s$ 個の等式拘束条件により他 の $s$ 個の成分を定めることができる。ゆえに、 独立成分を設計変数の一般変数（設計パラメー夕）と すれば、式(17)〜(19)を適用できる。もちろん、Pは荷 重のない状態でプレストレスの釣り合い条件を满足す 


\section{ることが必要である゙す。}

拘束条件は設計変数 $\mathrm{X}, \mathbb{A}, \mathbb{P}$ の許容領域を作り出して いる。最適化解析の計算中には、ある局所あるいは許 容点において、独立的拘束条件の数が隇ることが可能 である。ここで、最適化計算中にランクが一定となる 拘束条件（空間）を非退化的拘束条件（空間）

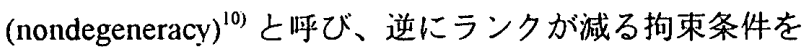
退化的拘束条件（榮間）(degeneracy) と呼ぶ。ここまで の解析では拘束空間が非退化的であると仮定している。 退化的 拘束空間の場合、最適化計算（反復計算）のス テップごとにJのランクをチェックし、非独立行と列 を取り出し、独立行と列のみを扱い、独立行に対応し ている変数を一般変数として扱う。

\section{3 設計パラメータの修正}

最適化計算の第 $k$ ステップで、目的関数の降下方向 d に沿って設計パラメータを修正する。

$$
\left(\begin{array}{l}
\mathbf{q} \\
\mathrm{a} \\
\mathbf{b}
\end{array}\right)^{k+1}=\left(\begin{array}{l}
\mathbf{q} \\
\mathbf{a} \\
\mathbf{p}
\end{array}\right)^{k}+\alpha \mathbf{d}^{k}
$$

ここに 最適条件を満足するまで繰り返し計算すると最適解を 得ることができる。本論文で用いられる最適条件は原 則的に Kuhn and Tucker ${ }^{10.11}$ の条件である。

\section{4 不等式拘束条件について}

最適化計算の第 $k$ ステップで得られる点( $\left(\begin{array}{l}\mathbf{q} \\ a \\ \mathbb{p}\end{array}\right)^{k}$ が拘束 空間の境界に近付くと、

$$
\varphi_{i}(\mathbb{X}, \mathbb{A}, \mathbb{P})^{k}<0 ; \quad \varphi_{i}^{k} \approx 0, \quad(i=1, \ldots, t)
$$

が成り立つ。テイラー展開により、式(6)は上式の前提 で近似的に次式のように表される。

$$
\left\{\varphi_{i}\right\}^{k}+\alpha \mathbb{G d} \leq \mathbb{0} \Rightarrow \mathbb{G} \mathbb{d} \leq 0,
$$

但し、

$$
\mathbb{G}=\left(\left\{\varphi_{i}\right\}^{k} \nabla\right) \boldsymbol{J}^{\top}
$$

最適計算の第 $k+1$ ステップの点が拘束空間の外へ出な い上うに、この境界の近傍で降下方向』を修正するこ とが必要である。つまり、式(22)を満足するように』を
次のように修正する。

$$
d_{k}= \begin{cases}0 & \forall i, k: G_{i k} d_{k} \geq 0 \quad \vee \sum_{j=1}^{1} G_{i j} d_{j} \geq 0 ; \\ d_{k} \text { otherwise }\end{cases}
$$

式(20)の降下方向 d は上式により修正したものである。 よって、式(20)により得られる点が不等式条件を満足す るようになる。

\section{5 解析のアルゴリズム}

step 0 ：制約条件を満足している初期値 $(\mathbf{X}, \mathbf{A}, \mathbf{P})^{0}$ を決める。

step $1:$ 式(7)により変位ベクトルDを求め、式 (17)でJacobi マトリックス Jを計算する。 step $2:$ 式(9) (13)により目的関数の降下方向 を求める。

step 3: 式(18)と式(24)によりdを得る。 もし、』ぇ0ならば、計算をストップ。 step $4:$ 式(20)により設計変数を修正する。 もし $\alpha=0$ なら、計算をストップする。 step $\mathbf{5}: F^{k+1}<F^{k}$ を確認した上で、 $k=k+1$ 、 step 1 に行く。

\section{4. 数値解析例題}

\section{1 例題の説明}

図 1 に示す tensegrity frame を例題として数值解析を 行った。最適化により求める未定設計変数は節点座標、 部材の断面積、そしてプレストレス軸力である。

荷重は鉛直等分布荷重であるが、各節点に作用して いる荷重は節点座標の関数となっている。また、剛性 目的関数には全域載荷(Full-loading case); 半域載荷(Halfloading case) そして 1/4域載荷 (Quarter-loading case) の 三種類の荷重ケースを採り入れ最適解析を行った。 ケーブルとポストのヤング係数はそれぞれ $1.90 \times 10^{6} \mathrm{~kg} / \mathrm{cm}^{2}$ と2.10 $\times 10^{6} \mathrm{~kg} / \mathrm{cm}^{2}$ である。

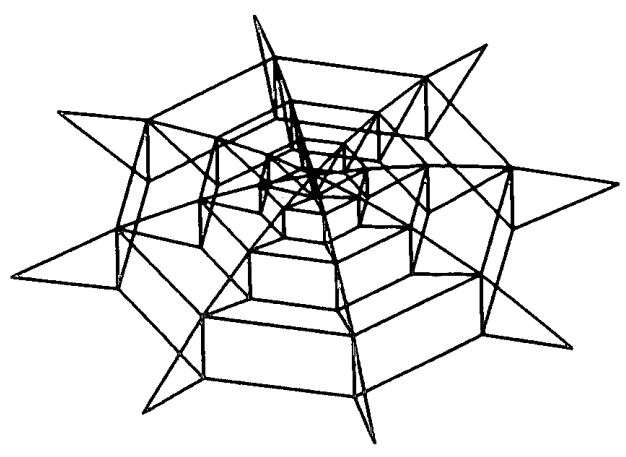

図 1 (a) 

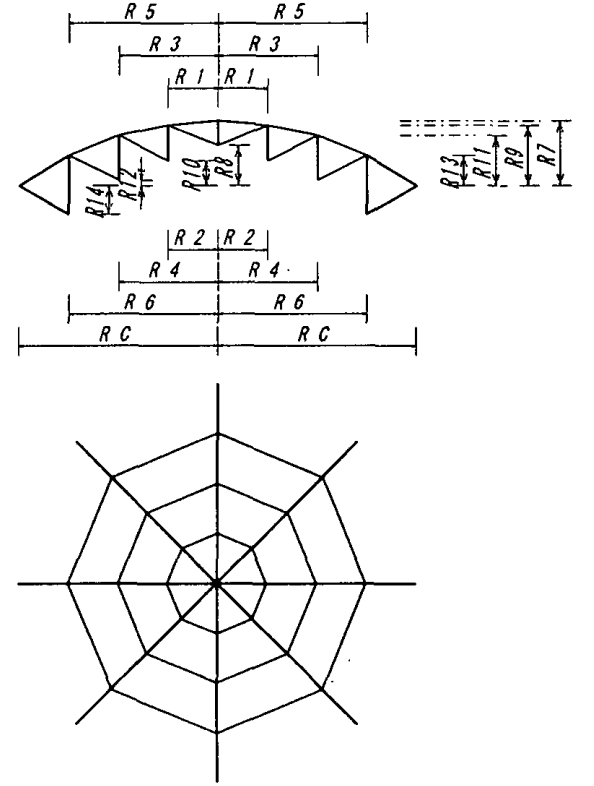

(b)

図 1 Tensegrity 椛造の例題

一般には、設計者は設計目的と各設計要件を分析し た上に重み係数を設定する。本例題のtensegrityに対し ては、全域荷重による変位が非常に小さく、非対称荷 重による変位が非常に大きいことが明らかである。大 きな変位を与える荷重ケースに対して構造を補強する ために、重み係数は $w_{1}=0.1 ; \quad w_{2}=0.5 ; \quad w_{3}=0.4$; $W_{1}=0.9 ; \quad W_{2}=0.1$ と設定されている。

\section{2 拘束条件亡設計パラメータ}

対称的な構造を得るために、図（1，b）に示すよ うにRI〜RI4を節点座標の設計パラメータとし、各節 点の座標はこれらの設計パラメー夕により得られる。 従って、幾何学的等式拘束条件が存在していない。

表2.1で示されるように $a_{1} \sim a_{18}$ は部材断面積の設計パ ラメータである。四つの層のポストのプレストレスは それぞれ均一であり、この四つのプレストレス値PI〜 P4（表 2、2.2に参照）はプレストレスの設計パラメー 夕とされている。

力学的等式拘束は、荷重のない状態でのプレストレ 又轨力の釣合い式である。力学的不等式拘束条件は、 荷重あるいはプレストレスによるケーブルの軸力が正 (テンション)であることである。ケーブルとポストの 軸力がその終局耐力より小さいことも不等式拘束条件 とされている。

\section{3 解析結果のまとめ}

初期形態と最適形態の各寸法を表 1、部材断面積と プレストレスの変化を表 2 で表している。

また、最適解（最適形態）に対して幾何学的非線形
椿造解析を行った。図 $3 \sim 5$ は荷重パラメー夕が5.5に おける、全域、半域と $1 / 4$ 域載荷による上部節点の鉛直 変位を表し、半域と $1 / 4$ 域荷重による上部節点の鉛直変 位が10〜30\%隇ることを示している。図 7 は幾何学的 非線形解析による荷重変位曲線を表している。最適化 解析の結果、構造のボリュームが $24.6 \%$ 減少すること が見られる（図6）。図8は繰り返し計算の収斂様子 を表している。

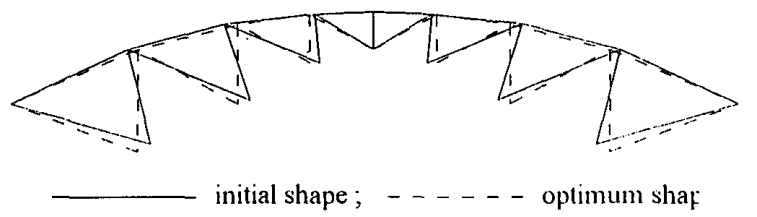

図 2 辈造断面の変化

表 1 各寸法：(cm)

\begin{tabular}{|l|c|c|}
\hline & initial & optimum shape \\
\hline$R C$ & 4000.00 & 4000.00 \\
\hline$R 1$ & 700.00 & 643.84 \\
\hline$R 2$ & 700.00 & 593.27 \\
\hline$R 3$ & 1500.00 & 1639.46 \\
\hline R4 & 1500.00 & 1364.80 \\
\hline$R 5$ & 2600.00 & 2708.33 \\
\hline$R 6$ & 2600.00 & 2454.04 \\
\hline$R 7$ & 100.00 & 1000.25 \\
\hline$R 8$ & 592.00 & 592.06 \\
\hline$R 9$ & 971.00 & 971.66 \\
\hline$R 10$ & 448.00 & 449.63 \\
\hline$R 11$ & 867.00 & 868.93 \\
\hline$R 12$ & 0.00 & 37.46 \\
\hline$R 13$ & 593.00 & 594.79 \\
\hline$R 14$ & -520.00 & -442.83 \\
\hline
\end{tabular}

表2 部材断面糟とプレストレス軸力

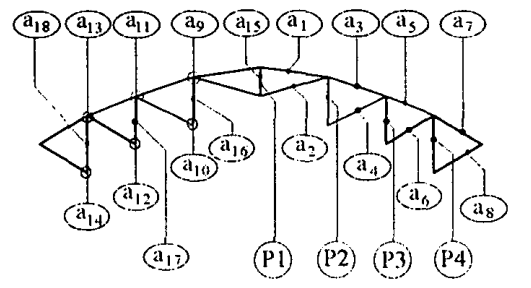

表 2.1 部材の断面積 $\left(\mathrm{cm}^{2}\right)$ :

\begin{tabular}{|c|c|c|c|c|c|}
\hline & initial & optimum & & initial & optimum \\
\hline $\mathrm{a}_{1}$ & 20.00 & 15.61 & $\mathrm{a}_{10}$ & 20.00 & 16.75 \\
\hline $\mathrm{a}_{2}$ & 20.00 & 14.96 & $\mathrm{a}_{11}$ & 20.00 & 12.19 \\
\hline $\mathrm{a}_{3}$ & 20.00 & 14.14 & $\mathrm{a}_{12}$ & 20.00 & 12.72 \\
\hline $\mathrm{a}_{4}$ & 20.00 & 13.43 & $\mathrm{a}_{13}$ & 20.00 & 6.75 \\
\hline $\mathrm{a}_{5}$ & 20.00 & 12.67 & $\mathrm{a}_{14}$ & 20.00 & 7.36 \\
\hline $\mathrm{a}_{6}$ & 20.00 & 11.20 & $\mathrm{a}_{15}$ & 85.00 & 84.67 \\
\hline $\mathrm{a}_{7}$ & 20.00 & 10.39 & $\mathrm{a}_{16}$ & 85.00 & 81.53 \\
\hline $\mathrm{a}_{8}$ & 20.00 & 9.73 & $\mathrm{a}_{17}$ & 130.00 & 124.36 \\
\hline $\mathrm{a}_{9}$ & 20.00 & 16.64 & $\mathrm{a}_{18}$ & 130.00 & 122.79 \\
\hline
\end{tabular}


表 2.2 プレストレス軸力 $(\mathrm{kg})$ :

\begin{tabular}{|c|c|c|c|c|}
\hline & P1 & P2 & P3 & P4 \\
\hline initial & -2500.000 & -3000.000 & -10000.000 & -50000.000 \\
\hline optimum & -2500.000 & -3000.021 & -10000.204 & -50000.044 \\
\hline
\end{tabular}

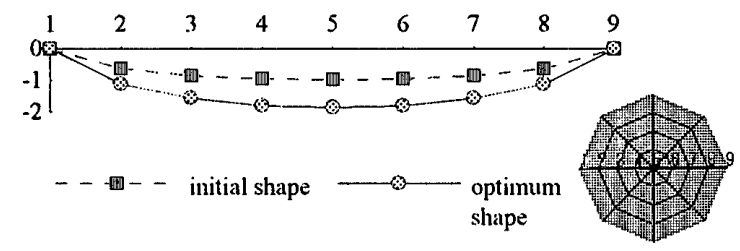

図 3 Full-loading case による上部節点の汴位

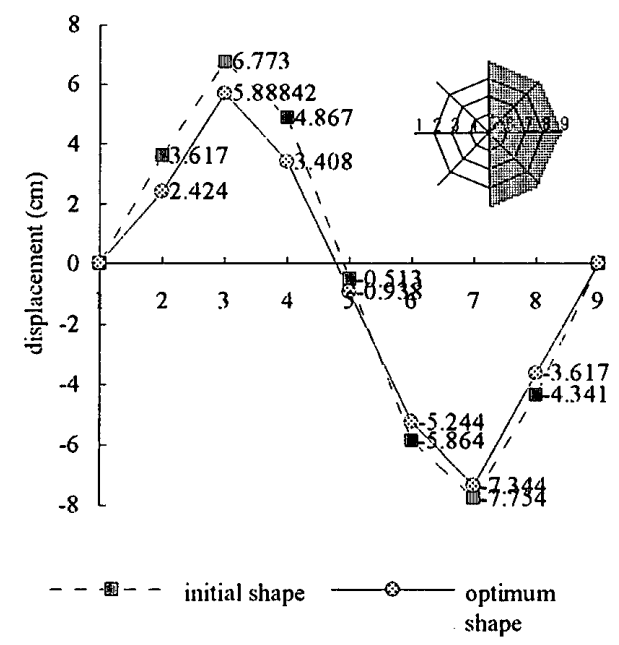

図 4 Half-loading case による上部節点の変位

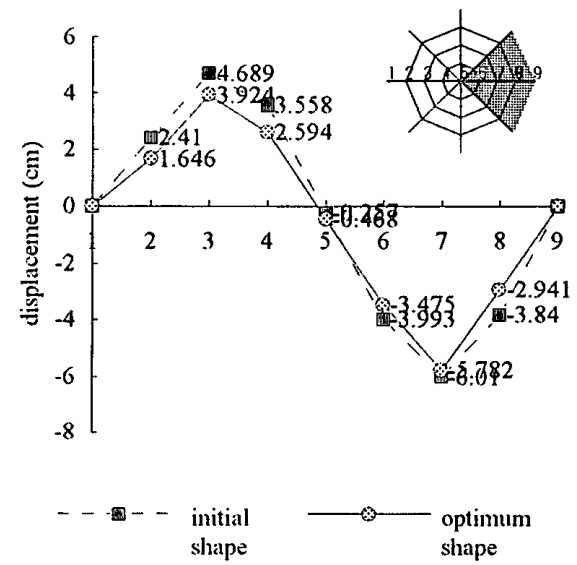

図 5 Quarter-loading case による上部節点の変位

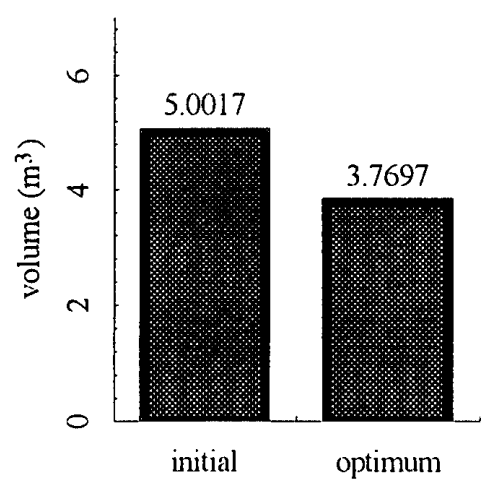

図6 ボリュームの変化
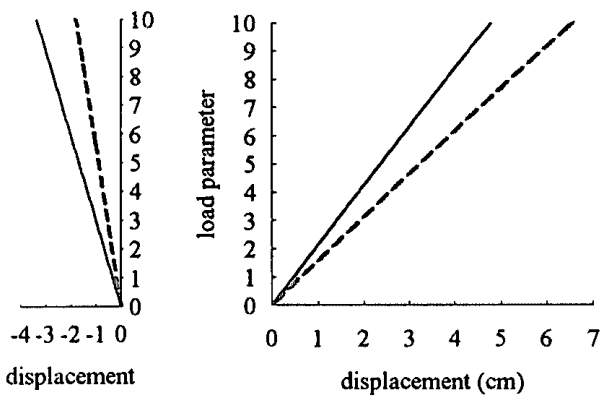

(a) Full-loading case (point 5) (b) Half-loading case (point 3)

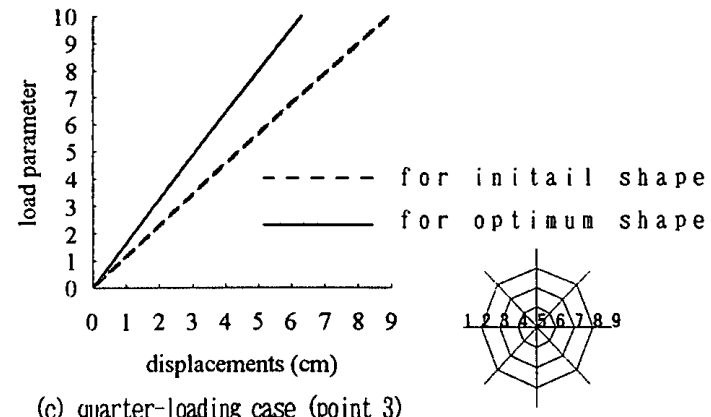

(c) quarter-loading case (point 3)

図 7 荷重変位曲線の変化 

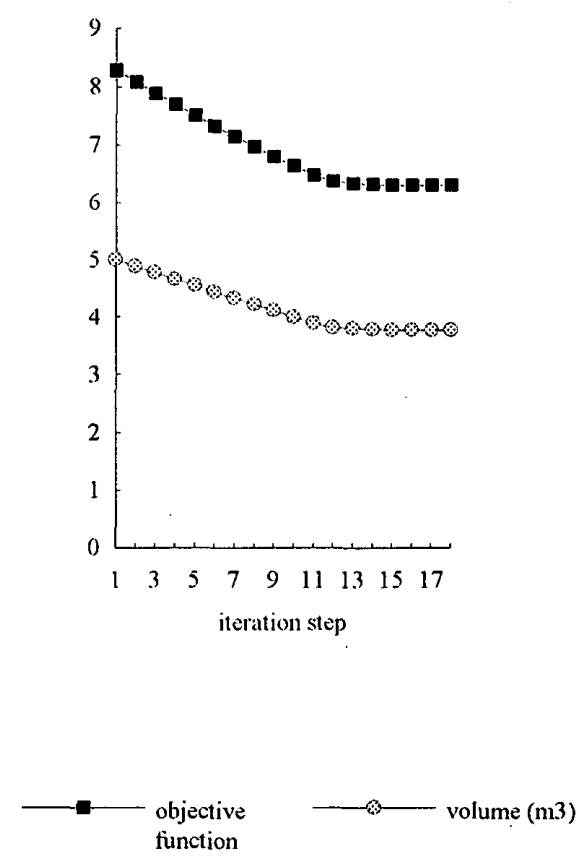

\section{図 8 目的関数の収斂}

\section{5.おわりに}

本解析手法により、例題のtensegrity の節点変位が 10 〜30\%減り、ボリュームが24.6\%減ることが見られた。

例題では全域、半域、そして $1 / 4$ 域載荷の三種類の 荷重ケースを採り入れ最適化解析を行ったが、実際の 設計では、最も影響の大きな荷重ケースを採り入れる ようになる。また、この方法により得られる最適形態 は重み係数に依存するため、具体的な設計要件を勘案 し、適切な重み係数を決めることが重要である。
本論文で紹介された多目的形態最適化は、設計方穼 の近傍に、より良い構造形態を見付け出し、設計厅案 の改良において重要な手法になると考えられる。

\section{管考文虾}

1) V. Pareto, Cours d-Economie Politique, Rouge, Lausanne, Switzerland, 1896.

2) W. Stadler, Preference Optimality and Applications of Pareto Optimality, Multicriterion Decision making (A. Marzollo and G. Leitmann, eds.), CISM Courses and Lectures, Springer-Verlag, Berlin, Germany, 1975.

3) Pei Shan Chen, Masaru Abe, Mamoru Kawaguchi, Shape of Tensegrity Frames Having An Optimum Rigidity, 4th Conference on Space structures, University of Surrey, UK., Sep. 5-10, 1993.

4) Pei Shan Chen and Mamoru Kawaguchi, Minimum-Deformation-Shape of Prestressed Bar-Structures, Nonlinear Analysis And Design for Shell and Spatial Structures, Proceeding of The Seiken-IASS Symposium Oct. 19-22, 1993, Tokyo, Japan.

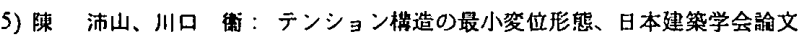
報告集、第468号. 1995 年 2 月。pp.101 108

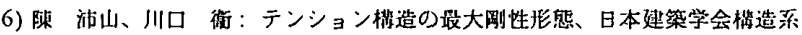

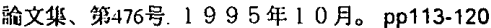

7) Wolfiam Stadler: Multicriteria Optimization in Engineering and in the Sciences, Plenum Press, 1988.

8)H.Adeli, Advances in Design Optimization, Chapman \& Hall, 1994 9) 半谷 㭲彦, 川口 健一: 形態解析、計算力学と C A E シリス 5、培風館、 1991。

10) 今锦浩、山下 浩: 非線形計画法、日科技連、1978。

11)M. Minoux : Mathematical Programming (Theory and Algorithms), Jolun Wiley and Sons, 1983.

（1995年 8 月 14 日原稿受理，1995年11月 9 日採用決定） 